1 Doutoranda em Letras - Língua, Literatura e Cultura Italianas pela Universidade de São Paulo. Mestra em Letras - Língua, Literatura e Cultura Italianas pela mesma Universidade.

http://orcid.org/0000-0002-1388-2191

E-mail: lucianedonascimento@gmail.com

2 Professor Doutor (MS-3 - nivel 2) da Universidade de São Paulo, onde atua na graduação e na pósgraduação (mestrado e doutorado). Concluiu o Universidade de São Paulo (2002) e o doutorado em Linguística na mesma universidade (2007).

http://orcid.org/0000-0001-7577-368X.

E-mail: esantoro@usp.br

Recebido em: 15/05/2019

Aprovado em: 18/08/2019.

Publicado em: 27/12/2019.

Endereço:

Ensade de São Paulo. Av. Prof. Luciano , 403 CEP: 05508-900 - Cidade Universitária

\section{Ordens e pedidos em língua italiana: um estudo da percepção de falantes nativos e aprendizes brasileiros}

\author{
Orders and requests in Italian: a study of the perception of native speakers and Brazilian learners
}

Luciane Nascimento Spadotto ${ }^{1}$

Universidade de São Paulo, Faculdade de Filosofia Letras e Ciências Humanas, São Paulo, SP. Brasil.

Elisabetta Santoro ${ }^{2}$

Universidade de São Paulo, Faculdade de Filosofia Letras e Ciências Humanas, São Paulo, SP, Brasil.

\section{RESUMO}

O objetivo do estudo é investigar ordens e pedidos em língua italiana, identificando os elementos que caracterizam e diferenciam esses dois atos de fala, a partir da percepção de falantes nativos e aprendizes brasileiros. 0 instrumento elaborado para a coleta dos dados apresentava aos informantes interações verbais entre falantes nativos de italiano (role plays, gravados em áudio e vídeo, e diálogos extraídos de material cinematográfico), que deveriam ser classificadas como 'ordem' ou como 'pedido' com uma justificativa para a escolha. Havia também um terceiro campo em aberto ('outro'). Analisando as respostas de 40 italianos e 40 aprendizes brasileiros, observamos que ordens e pedidos em língua italiana são diferenciados pela estrutura linguística e pelos elementos contextuais que envolvem a interação. A comparação dos resultados não revelou diferenças significativas na classificação dos dois atos de fala por parte de falantes nativos e brasileiros. Contudo, foi possível constatar que, enquanto os informantes italianos recorreram com maior frequência a elementos de tipo pragmático e prosódico para justificar suas respostas, os aprendizes brasileiros se basearam na maior parte dos casos em aspectos de tipo pragmalinguístico. Palavras-chave: Ordens. Pedidos. Atos de fala. Língua italiana. Aprendizes brasileiros.

\section{ABSTRACT}

The aim of the study is to investigate orders and requests in Italian, identifying the elements that characterize and distinguish these two speech acts in the perception of native speakers and Brazilian learners. The data-gathering instrument presented to the informants verbal interactions between native Italian speakers (role plays, recorded in audio and video, and dialogues extracted from cinematographic material), which should be classified as "order" or "request" with a justification for the choice. There was also a third open field ("other"). Analyzing the responses of 40 Italians and 40 Brazilian learners, we found that orders and requests in Italian are differentiated by linguistic structure and contextual elements that involve interaction. The comparison of the results did not reveal significant differences in the classification of the two speech acts by native and Brazilian speakers. However, it was possible to verify that, while Italian informants used more frequently pragmatic and prosodic elements to justify their answers, Brazilian learners' choices were mostly based on pragmalinguistic aspects.

Keywords: Orders. Requests. Speech acts. Italian language. Brazilian learners. 


\section{INTRODUÇÃO}

Os

livros didáticos, que muitas vezes simplificam e descontextualizam a língua estrangeira, são na maior parte dos casos uma referência insuficiente, quando se quer trazer para a sala de aula a complexidade da comunicação (MARTíNEZFLOR, 2008; NUZZO, 2013). A problematização dos aspectos pragmáticos da língua é escassa ou ausente e há questões não contempladas que podem criar dificuldades quando professores e aprendizes buscam ir além da gramática e do léxico.

Ensinar o uso de um modo verbal como o imperativo da língua italiana a aprendizes brasileiros é um exemplo de como a falta de reflexão sobre algumas implicações que vão além da "norma" estabelecida pela gramática pode limitar ou até confundir. Nos manuais de italiano para estrangeiros, o imperativo é, de fato, apresentado como a forma linguística que pode ser utilizada para a realização de diversos atos de fala como ordens, conselhos, pedidos, instruções etc. Há, portanto, uma distinção entre uma única forma e suas possíveis funções, mas é raro encontrar explicações ou exemplos claros sobre os elementos que os diferenciam.

Para distinguir um conselho de um pedido, é possível dizer, levando em consideração um de seus traços distintivos, que o conselho é um ato que, quando proferido, visa ao benefício do ouvinte, enquanto o pedido é realizado para que o falante obtenha algo em seu próprio benefício. Mas qual seria então a diferença entre atos cujo objetivo é o mesmo, como no caso da ordem e do pedido, sendo que ambos visam ao benefício do falante?

A motivação para realizar uma pesquisa sobre ordens e pedidos em língua italiana surgiu a partir desses questionamentos, com o objetivo de identificar os elementos que caracterizam esses dois atos de fala e criam distinções entre eles que podem ser úteis também para entender melhor seu funcionamento e, portanto, permitir também uma abordagem mais abrangente no ensino. Utilizando como referência a percepção de falantes nativos ${ }^{3}$ e aprendizes brasileiros de italiano, nos propomos a verificar se e em que medida pode

Mesmo controverso (ver, entre outros, Schmitz, 2013), o conceito de falante nativo ainda é útil em pesquisas como esta que queiram comparar usos linguísticos por parte de grupos com características distintas. Aqui, cientes de que se trata de uma abstracão, consideraremos que falante nativo é aquele que aprendeu e usa uma determinada língua na familia e no percurso escolar. variar o reconhecimento desses dois atos de fala para refletir, a partir disso, sobre as possíveis implicações para o ensino e a aprendizagem de línguas, no nosso caso o italiano no Brasil. Além disso, a pesquisa pode trazer luz não apenas sobre analogias e diferenças culturais entre italianos e brasileiros, mas também, de forma mais geral, sobre a influência que a diferente interpretação de atos de fala como ordens e pedidos pode ter nas relações interculturais.

\section{ORDENS E PEDIDOS: CLASSIFICAÇÃo E CARACTERÍSTICAS}

A Pragmática, como área da Linguística moderna refere-se, segundo Crystal:

[...] ao estudo da língua do ponto de vista dos usuários, especialmente das escolhas que fazem, das restrições com as quais se deparam enquanto utilizam a língua na interação social, e dos efeitos que seu uso tem sobre os outros participantes durante o ato comunicativo (CRYSTAL, 2008, p. 379 , tradução nossa) ${ }^{4}$.

Desse modo, do ponto de vista da Pragmática, embora sejam dois atos de fala distintos, o pedido e a ordem são proferidos com intuito bastante semelhante: o falante busca, como efeito do ato proferido, levar seu interlocutor a fazer uma ação que lhe traga vantagens futuras.

Conforme as teorias dos atos de fala desenvolvidas por Austin (1990), Searle (2002) e Sbisà (2009), ordens e pedidos podem apresentar semelhanças, a ponto de pertencerem a uma mesma categoria, e diferenças, quando se observa sua força ilocutória e o efeito que o proferimento de tais atos causa no ouvinte. Austin (1990) afirma que tanto ordens quanto pedidos são atos "exercitivos", isto é, consistem no exercício de poder, direito ou influência, junto com súplicas, orientações, recomendações etc. Para Searle (2002), pedido e ordem também estão dentro da mesma categoria: são considerados "diretivos", ou seja, atos, cujo propósito ilocutório "consiste no fato de que são tentativas [...] do falante

Do original: [...] to the study of language from the point of view of the users, especially of the choices they make, the constraints they encounter in using language in social interaction, and the effects their use of language has on the other participants in an act of communication. 
de levar o ouvinte a fazer algo" (SEARLE, 2002, p. 21), porém são diferenciados pela sua força ilocutória. Diferentemente do que é apresentado, em termos de categorização, por Austin e Searle, Sbisà (2009, p. 92) afirma que pedidos e ordens podem estar naturalmente em categorias separadas, já que, para a autora, a ordem é explicitamente categorizada como ato exercitivo, com o falante que tem o "poder" de atribuir um "dever" ao destinatário, enquanto o pedido é um ato definido "comportativo" porque muda o comportamento do destinatário a quem o falante atribui um "poder fazer".

Além de classificar os atos de fala, os trabalhos de Austin, Searle e Sbisà fazem considerações sobre as condições ideais, depreendidas pela análise do contexto ${ }^{5}$, para que um ato seja realizado com sucesso. Austin chama tais casos de "condições de felicidade" ou adequação, quando um ato, ao ser proferido, atende a uma ou mais condições para sua realização. No caso das ordens, poderia ocorrer um caso de "infelicidade" ou inadequação, se o ouvinte não reconhecesse a autoridade do falante e, assim, não aceitasse $o$ ato, ou se o falante não tivesse a autoridade necessária que lhe permitisse o proferimento de uma ordem. Searle evidencia os mesmos aspectos considerados por Austin, ou seja, para o proferimento de ordens é necessária uma regra preparatória: o falante deve estar em uma posição de autoridade em relação ao ouvinte. No caso das ordens, que são atos exercitivos, Sbisà também afirma que a condição fundamental para sua realização é a da apropriação, uma vez que o falante, ao proferir esse tipo de ato, deve estar na posição adequada para exercer o poder. No entanto, na perspectiva da autora, a função das condições de adequação ou felicidade vai também em outra direção (não necessariamente contrária), se comparada àquilo que afirmam Austin e Searle: as circunstâncias adequadas para o proferimento dos atos são aspectos intersubjetivos, isto é, fruto de um acordo entre os participantes e, além disso, são demasiadamente vagas para que uma tipologia possa apoiar-se nelas. A estratégia que a autora estabelece então para considerar essas condições é combiná-las com os efeitos ilocutórios dos atos.

Partindo das reflexões sobre o contexto de Sbisà (2002) e Bazzanella (2008), para este trabalho, consideramos que o contexto pode ser composto por dois níveis que interagem entre si: o global (ou contexto "dado") e o local (ou contexto "construído"). 0 primeiro refere-se aos elementos prevalentemente sociolinguísticos de uma determinada situação comunicativa, entre os quais, os participantes, o local onde ocorre a interação, os agentes instrumentais etc.; enquanto no segundo, estão presentes componentes tanto de tipo cognitivo, que permitem que os falantes façam inferências, quanto de tipo linguístico, como o cotexto, as formas linguísticas e as mudanças de código induzidas pela própria interação.

Letrônica | Porto Alegre, v. 12, n. 3, out.-dez 2019: e34170
Outro aspecto que é importante lembrar, para além das diferenças de classificação que acabamos de expor, é que tanto ordens quanto pedidos são considerados, com base nos estudos de Brown e Levinson (1987), "Face Threatening Acts" (doravante FTAs), ou seja, atos ameaçadores da face, pois colocam em risco a face dos interlocutores (GOFFMAN, 1967) os quais, para avaliar a "dificuldade" de um FTA, se apoiam em três fatores: (i) a distância social entre os interlocutores (Social Distance - D); (ii) o poder relativo entre eles (Relative Power - P); e (iii) o nível de imposição do ato ilocutório (Absolute Rank of Imposition - R) (Brown e Levinson, 1987, p. 74). ${ }^{6}$

Visto que, ao realizar tanto uma ordem quanto um pedido, o falante está tentando fazer com que seu interlocutor aja em seu benefício, a ameaça que provém desses dois atos de fala tem um caráter duplo. A face do falante dita "positiva", isto é, seu desejo de aprovação e aceitação social, é ameaçada porque sua ordem ou seu pedido estão naturalmente submetidos à possibilidade de uma recusa, o que pode configurar rejeição por parte do ouvinte. Por sua vez, a face "negativa" do ouvinte, que indica sua liberdade de ação, também está ameaçada, já que uma ordem ou um pedido podem limitar a liberdade do outro e fazer com que se sinta obrigado a desviar seu comportamento.

0 particular caráter ameaçador de ordens e pedidos faz com que esses atos possam ser realizados por diversas estruturas linguísticas. Nos estudos de Searle, encontramos, além da taxonomia dos atos ilocutórios baseada no isolamento da força ilocutória e do ato proposicional, a classificação de atos de fala indiretos, ou seja, os casos em que um determinado ato ilocutório é realizado por meio de outro. Em alguns estudos empíricos, desenvolvidos com o propósito de verificar como se manifestam os atos de fala, há resultados que apontam para as variedades de formas utilizadas para a realização de ordens e pedidos. Kerbrat-Orecchioni (2005), por exemplo, trata do assunto quando aborda os atos de fala que denomina "pergunta" e "solicitação", para ilustrar (i) os problemas de definição e delimitação dos atos de fala e (ii) a necessidade

6 Embora tenha sido contestado, sobretudo no que diz respeito à pretensão da universalidade e, em especial, por pesquisadores que estudam (des)cortesia em sociedades não-ocidentais (ver, entre outros, Clancy, 1986, 1989; Hill et al., 1986; Ide, 1989; Matsumoto, 1988, 1989; Gu, 1990), o modelo de Brown e Levinson (1987) continua sendo a referência mais utilizada para estudos da área da Pragmática, já que as dimensões identificadas pelo autores sintetizam algumas das principais variáveis que é preciso levar em conta. 
de distinguir estrutura formal e valor ilocutório de um enunciado. A autora busca conciliar os pontos de vista linguístico e pragmático e define que:

1. convém distinguir o pedido de um "dizer" (pergunta) e de um "fazer" (solicitação);

2. a pergunta e a solicitação fazem parte de uma mesma categoria maior, a dos pedidos;

3. a ordem é um tipo particular de solicitação.

A pergunta tem como principal finalidade obter de seu destinatário uma informação, comportando numerosas variantes, que podem se contrapor utilizando diferentes critérios. Já a solicitação tem como principal característica a diversidade de suas formulações, o que pode ser correlacionado com o caráter fundamentalmente 'ameaçador' desse ato de fala. Desse modo, KerbratOrecchioni (2005) diz serem as ordens um caso particular de solicitação que se caracteriza por seu teor autoritário e, quando se atém ao caráter formal, pela utilização de uma fórmula explicitamente performativa como "Ordeno que você feche a porta", ou do modo imperativo "Feche a porta".

Esse mesmo fundamento é encontrado no trabalho de Nuzzo (2007), realizado com o objetivo de observar a evolução da competência pragmática ${ }^{7}$ de aprendizes de italiano L2 e se concentra em uma análise da realização de três atos de fala, a saber: o pedido, o pedido de desculpas e a reclamação. Foram gravados em áudio 80 diálogos entre falantes nativos italianos que, por meio de um role play aberto espontâneo, realizavam os três atos de fala. No que diz respeito, em especial, aos pedidos, a autora definiu sete categorias, dentre as quais está a ordem, caracterizada, em sua classificação, pela utilização do modo imperativo do verbo principal: oh passami un po' d'acqua [oh me passe um pouco d'água].

Contudo, o modo imperativo é apontado também como um dos meios para a realização de pedidos, segundo outros estudos empíricos desenvolvidos no campo de ensino da língua italiana. Vedder (2007) afirma que em italiano, além do imperativo, $o$ ato do pedido pode ser realizado pelo verbo performativo

Para a definição de competência pragmática adotada neste trabalho, ver Seção 2. chiedere [pedir], pela pergunta ou indiretamente por meio de um ato constatativo, ou seja, depende, sobretudo, da inferência do interlocutor.

Esse também é o ponto de partida em Santoro (2013) que, ao escolher o pedido como ato de fala para estudar a competência pragmática, afirma que esse ato de fala pode ser realizado com um verbo performativo, com o uso de um verbo no modo imperativo, com uma pergunta, ou indiretamente, com um ato constatativo.

Tais concepções alinham-se com o que é apresentado por algumas gramáticas da língua italiana, nas quais se afirma que o modo imperativo não é apresentado como uma forma linguística usada exclusivamente para o proferimento de ordens, pois pode também ser utilizado na realização de pedidos. Moretti e Orvieto (1984), por exemplo, defendem que tal modo pode ser utilizado para o proferimento de diversos atos de fala, diferenciados, entre outras coisas, a partir da entonação utilizada pelo falante. Serianni (1991) também assevera que o modo imperativo não é usado exclusivamente para o proferimento de ordens, listando um amplo número de atos de fala que podem ser realizados por meio desse modo verbal. Assim como Moretti e Orvieto (1984), o linguista considera ser a entonação um dos elementos que podem diferenciar os atos proferidos por meio do imperativo, acrescentando também os verbos utilizados pelo falante e a utilização de modificadores linguísticos, cuja função pode ser reforçar ou atenuar a força ilocutória do ato.

\section{A COMPETÊnCia PRAgMática EM LÍngUa MATERNA (L1) E LÍNGUA ESTRANGEIRA (L2)}

A competência pragmática, considerada parte da competência comunicativa, refere-se à capacidade de reconhecer e adequar ao contexto as escolhas linguísticas realizadas pelos falantes. Fenômenos que podem ser encontrados em diferentes aspectos da língua em uso como o proferimento de atos de fala, o uso das regras de (des)cortesia ou polidez e os elementos modificadores permitem observar e analisar a competência pragmática tanto em língua materna (L1) quanto em língua estrangeira (L2).

Pensando, em especial, no desenvolvimento da competência pragmática em L2, podemos retomar o que afirma Nuzzo: 
[...] aprender a gramática e o léxico de uma língua não é suficiente para saber usá-la de modo eficaz. 0 conhecimento de uma língua inclui também a capacidade de operar as escolhas em relação ao contexto comunicativo em que se encontra. Essa capacidade, que chamamos competência pragmática, pressupõe, de um lado, o conhecimento das normas sociais que regulam o agir linguístico em determinada cultura, de outro, o conhecimento das formas linguísticas associadas às múltiplas manifestações do agir linguístico naquela mesma cultura [...] (2012, p. 23, tradução nossa). ${ }^{8}$

Portanto, o que se considera essencial é, por um lado, o aspecto dito sociopragmático, isto é, a maneira como as normas sociais influenciam os comportamentos linguísticos; e, por outro, aspectos chamados pragmalinguísticos, mais intrinsecamente ligados à seleção de estratégias e elementos linguísticos específicos (LEECH, 1983).

Outro fator que precisa ser levado em conta é a "consciência (meta) pragmática", pois com o desenvolvimento da competência nessa dimensão da língua, os falantes tendem a tornar-se capazes não apenas de usar, mas também de avaliar os efeitos de suas escolhas linguísticas e o funcionamento da língua dentro de cada contexto.

0 processo é ainda mais complexo no ensino e na aprendizagem de uma L2 e recebeu, durante décadas, pouca atenção. Só em épocas mais recentes começou a ser realizado um maior número de estudos nessa área, alguns dos quais estão reunidos no livro Pragmatics and Language Teaching, organizado por Rose e Kasper (2001) e considerado referência para a discussão do tema. A obra contribuiu a definir questões essenciais no debate sobre o ensino e a aprendizagem da Pragmática, que se concentram, sobretudo, na reflexão sobre como pode ser aprendida essa competência e sobre se e como pode ser ensinada. Embora não confirmada por trabalhos posteriores entre os quais o de Vedder (2007), uma das principais conclusões a que chegaram os estudos (SALSBURY; BARDOVI-HARLIG, 2001) é que a competência pragmática se desenvolveria depois

Do original: [...] apprendere la grammatica e il lessico di una lingua non è sufficiente per saperla usare efficacemente. La conoscenza di una lingua include anche la capacità di operare delle scelte in relazione al contesto comunicativo in cui ci si trova. Questa capacità, che chiamiamo competenza pragmatica, presuppone da un lato la conoscenza delle norme social che regolano l'agire linguistico in una determinata cultura [ ] dall'altro la conoscenza delle forme linguistiche associate alle molteplici manifestazioni dell'agire linguistico in quella stessa cultura. da competência linguística. Há mais uma questão que merece destaque: em todos os casos, os estudos parecem apontar para a insuficiência da exposição a contextos de uso de uma determinada língua (mesmo em situações de imersão) e, portanto, para a necessidade de instruções específicas ${ }^{9}$.

\section{OS MODIFICADORES LINGUÍSTICOS}

Dependendo do nível de análise linguística no qual se inserem, os modificadores podem ser subdivididos em morfossintáticos, lexicais e discursivos e têm a função de calibrar a força ilocutória do ato de fala, além de ser marcas da relação intersubjetiva estabelecida pelos participantes da interação. No que diz respeito à sua classificação, o estudo já mencionado, realizado por Nuzzo (2007), apresenta uma proposta, que decidimos adotar na nossa pesquisa, com o objetivo de selecionar os exemplos de ordens e pedidos que seriam submetidos à avaliação dos informantes.

Na classificação de Nuzzo (2007), elaborada a partir do material coletado para o desenvolvimento de sua pesquisa, os trabalhos utilizados como referência foram os de Blum-Kulka et al. (1989), Trosborg (1995), Márquez Reiter (2000), Barron (2003), Achiba (2003) e Schauer (2004), concentrados em analisar pedidos em âmbito intercultural ou interlinguístico.

Além disso, cabe ressaltar que, para localizar os modificadores lexicais e morfossintáticos, Nuzzo (2007) segue o critério sugerido por Blum-Kulka et al. (1989, p. 19), isto é, os considera elementos opcionais do ponto de vista tanto gramatical quanto semântico, ou seja, elementos que têm uma função exclusivamente pragmática. No Quadro 1, seguem as categorias:

Além dos capítulos contidos em Kasper e Rose (2001), para uma revisão dos principais trabalhos que trataram dessa questão e dos estudos que se dedicaram, em especial, ao italiano como L2, ver Nuzzo e Santoro (2017). 
QUADRO 1 - Classificação dos modificadores em Nuzzo (2007)

\begin{tabular}{|c|c|c|}
\hline \multicolumn{2}{|c|}{ MODIFICADORES MORFOSSINTÁTICOS } & \multirow{2}{*}{ EXEMPLOS } \\
\hline TIPO DE MODIFICADOR & FUNÇÃo & \\
\hline $\begin{array}{l}\text { Condizionale } \\
\text { (Futuro do pretérito) }\end{array}$ & $\begin{array}{l}\text { Causa um distanciamento, faz parecer } \\
\text { que o que é dito está distante da reali- } \\
\text { dade. }\end{array}$ & $\begin{array}{l}\text { Ci sarebbe...; Non avrebbe... } \\
\text { (Haveria...; não teria...) }\end{array}$ \\
\hline $\begin{array}{l}\text { Imperfetto } \\
\text { (Pretérito imperfeito) }\end{array}$ & $\begin{array}{l}\text { Tem como objetivo, assim como o con- } \\
\text { dizionale, distanciar da realidade o que } \\
\text { é dito. }\end{array}$ & $\begin{array}{l}\text { Mi potevi dare... } \\
\text { (Você podia me dar...) }\end{array}$ \\
\hline $\begin{array}{l}\text { Incassatura } \\
\text { (Encaixe) }\end{array}$ & $\begin{array}{l}\text { Pode introduzir o ato de fala e é utilizado } \\
\text { frequentemente junto do condizionale ou } \\
\text { do imperfetto, criando a ideia de distân- } \\
\text { cia a respeito do enunciado. }\end{array}$ & $\begin{array}{l}\text { Volevo sapere se... } \\
\text { (Queria saber se...) }\end{array}$ \\
\hline $\begin{array}{l}\text { Negazione dell'interro- } \\
\text { gativa } \\
\text { (Negação da interrogativa) }\end{array}$ & $\begin{array}{l}\text { Através da negação, formula-se uma } \\
\text { pergunta, cuja função parece ser de } \\
\text { verificação ou confirmação. Além disso, } \\
\text { tem o efeito de afastar ou reduzir a força } \\
\text { ilocutória do ato de fala. }\end{array}$ & $\begin{array}{l}\text { Non è che... } \\
\text { (Você não pode me empres- } \\
\text { tar...?; Não sei se...; Será } \\
\text { que... ?) }\end{array}$ \\
\hline \multicolumn{3}{|c|}{ MODIFICADORES LEXICAIS } \\
\hline $\begin{array}{l}\text { Attenuatori } \\
\text { (Atenuadores) }\end{array}$ & $\begin{array}{l}\text { Transmitem a ideia de minimização do } \\
\text { esforço que seria necessário para res- } \\
\text { ponder a um determinado ato de fala. }\end{array}$ & $\begin{array}{l}\text { Un po'...; un attimo... } \\
\text { (Um pouco...; Um momento) }\end{array}$ \\
\hline $\begin{array}{l}\text { Autoumiliatori } \\
\text { (Auto-humilhadores) }\end{array}$ & $\begin{array}{l}\text { Colocam em evidência um defeito, ou } \\
\text { uma falta, do falante, apresentando-o } \\
\text { como responsável pela situação que o } \\
\text { leva a enunciar o ato de fala. }\end{array}$ & $\begin{array}{l}\text { Come sempre, mi sono } \\
\text { dimenticato... } \\
\text { (Como sempre, esqueci...) }\end{array}$ \\
\hline
\end{tabular}

\begin{tabular}{|c|c|c|}
\hline \multicolumn{3}{|c|}{ MODIFICADORES LEXICAIS } \\
\hline $\begin{array}{l}\text { Blanditori } \\
\text { (Aduladores) }\end{array}$ & $\begin{array}{l}\text { Ressaltam as capacidades do ouvinte } \\
\text { com intuito de persuadi-lo. }\end{array}$ & $\begin{array}{l}\text { Mi risolvi sempre i problemi } \\
\text { (Você, que sempre resolve } \\
\text { meus problemas,...) }\end{array}$ \\
\hline $\begin{array}{l}\text { Dubitatori } \\
\text { (Duvidadores) }\end{array}$ & $\begin{array}{l}\text { Transmitem um tipo de dúvida a respei- } \\
\text { to da realização do ato de fala e, desse } \\
\text { modo, reduzem as expectativas. }\end{array}$ & $\begin{array}{l}\text { Per caso; forse } \\
\text { (Por acaso..., Talvez...) }\end{array}$ \\
\hline $\begin{array}{l}\text { Rafforzatori } \\
\text { (Reforçadores) }\end{array}$ & Enfatizam a importância do ato de fala. & $\begin{array}{l}\text { Urgentemente; davvero; } \\
\text { próprio } \\
\text { (Urgentemente; realmente) }\end{array}$ \\
\hline \multicolumn{3}{|c|}{ MODIFICADORES DISCURSIVOS } \\
\hline $\begin{array}{l}\text { Fatismi } \\
\text { (Fatismos) }\end{array}$ & $\begin{array}{l}\text { Estabelecem um contato direto com o } \\
\text { interlocutor para aproximá-lo do falante. }\end{array}$ & $\begin{array}{l}\text { Sai; vedi } \\
\text { (Sabe...; Olha só...) }\end{array}$ \\
\hline $\begin{array}{l}\text { Marche di cortesia } \\
\text { (Marcas de cortesia) }\end{array}$ & $\begin{array}{l}\text { Usadas quando se recorre expressamen- } \\
\text { te à colaboração do falante. }\end{array}$ & $\begin{array}{l}\text { Per favore; dai } \\
\text { (Por favor; Por gentileza) }\end{array}$ \\
\hline $\begin{array}{l}\text { Richieste di accordo } \\
\text { (Pedidos de acordo) }\end{array}$ & $\begin{array}{l}\text { Buscam estabelecer um vínculo com o } \\
\text { interlocutor. }\end{array}$ & $\begin{array}{l}\text { Non è vero? } \\
\text { (Não é verdade?) }\end{array}$ \\
\hline $\begin{array}{l}\text { Riempitivi } \\
\text { (Preenchedores) }\end{array}$ & $\begin{array}{l}\text { Manifestam hesitação e mostram que a } \\
\text { formulação do ato cria um desconforto } \\
\text { para o falante. }\end{array}$ & $\begin{array}{l}\text { Cioè; insomma } \\
\text { (Ou seja; Enfim...) }\end{array}$ \\
\hline
\end{tabular}

Fonte: Elaborada pelas autoras.

A própria autora afirma que, por ter sido baseada no corpus analisado, a classificação poderia não esgotar a vasta gama das estratégias à disposição dos falantes para modificar seus atos de fala. Contudo, tal classificação revelou-se 
suficiente e permitiu dar conta dos elementos presentes nas interações escolhidas como base para esta pesquisa e também das respostas fornecidas pelos informantes. Além disso, cabe ressaltar que optamos por nos referenciar essencialmente no trabalho de Nuzzo (2007), já que, diferente dos estudos anteriores, sua classificação se baseou em um corpus de interações em língua italiana.

\section{OS OBJETIVOS DA PESQUiSA}

Com base na reflexão teórica sobre as características de ordens e pedidos e na convicção de que atos de fala "sensíveis" como esses possuem uma elevada variabilidade cultural, decidimos concentrar a pesquisa na comparação entre a percepção de aprendizes brasileiros de italiano e falantes nativos. Os informantes foram chamados a classificar exemplos selecionados e a justificar sua escolha, fornecendo assim dados que nos ajudaram a responder às três seguintes questões:

1. Quais são os elementos que caracterizam os atos de fala ordem e pedido em língua italiana, na percepção de falantes nativos (IT)?

2. Quais são os elementos que caracterizam os atos de fala ordem e pedido em língua italiana, na percepção de aprendizes brasileiros de italiano (BR)?

3. Quais analogias e diferenças se observam na comparação entre as avaliações de ordens e pedidos por parte de falantes nativos (IT) e aprendizes brasileiros (BR)?

Como consideramos que ordens e pedidos são diferenciados tanto por elementos associados à estrutura linguística usada pelos falantes, quanto pelo contexto que envolve a interação, nossa hipótese de partida era que haveria divergências não apenas na classificação, mas também na seleção das justificativas, tendo em vista que para um dos grupos o italiano é língua materna, para o outro, trata-se de uma segunda língua, o que poderia implicar o uso de referências linguísticas e culturais distintas.

\section{Metodologia dA PESQUiSA}

Nesta seção, são ilustrados os instrumentos e os procedimentos metodológicos utilizados para a realização da pesquisa. Além disso, são descritas as características dos informantes que participaram e a metodologia utilizada para a análise dos dados coletados.

\subsection{O QUESTIONÁRIO PARA A COLETA DOS DADOS}

Para atingir nossos objetivos, criamos um instrumento para a coleta dos dados que apresentava interações verbais entre falantes nativos de italiano (role plays, gravados em áudio e vídeo, e diálogos extraídos de material cinematográfico). A seleção dos vídeos foi feita, a partir do que é afirmado, sobre ordens e pedidos, pelas teorias e pelos estudos que estão guiando nosso trabalho. Optamos por interações com enunciados cujo ato de fala principal fosse proferido com o objetivo de levar o ouvinte a realizar uma ação futura em benefício do falante, característica comum a ordens e pedidos, conforme os estudos já citados de Austin (1990), Searle (2002) e Sbisà (2009). Em seguida, estabelecemos que as estruturas linguísticas dos enunciados presentes nessas interações deveriam ser de quatro tipos: (a) a pergunta sem modificador (PSM), entendida como ato de fala indireto, frequentemente utilizada, como afirma Searle, no proferimento dos atos diretivos; (b) a pergunta acompanhada de um modificador linguístico (PCM), cujo objetivo é alterar a força ilocutória do ato de fala; (c) o verbo principal no modo imperativo (ISM), que pode caracterizar, conforme indicam Kerbrat-Orecchioni (2005) e Nuzzo (2007), o ato de fala ordem; (d) o verbo principal no modo imperativo acompanhado do modificador (ICM), o que vai ao encontro do que afirma, por exemplo, Serianni (1991), quando ressalta que determinados elementos linguísticos podem atenuar a força ilocutória do ato que é proferido pelo modo imperativo, diferenciando-o de uma ordem.

Além disso, outro critério estabelecido para a seleção dos vídeos foi a relação entre os interlocutores. Como mencionado anteriormente, Brown e Levinson (1987) afirmam que esse é um dos fatores no qual os falantes se apoiam para avaliar a 'dificuldade' de um ato e, consequentemente, fazer suas escolhas linguísticas. No instrumento elaborado para a pesquisa, escolhemos ter representadas relações caracterizadas pelo eixo horizontal $(A=B)$, quando os 
dois falantes estão na mesma posição social, ou seja, quando há uma situação de igualdade entre os interlocutores; e pelo eixo vertical $(A>B$ e $A<B)$, quando um dos falantes se encontra, dentro do universo cultural da língua que estamos investigando, em uma posição social inferior ou superior em relação ao ouvinte.

A partir dos critérios de seleção descritos acima, escolhemos, no total, 16 vídeos, dos quais quatro são role plays gravados com falantes nativos (SANTORO, 2012) e 12 são cenas extraídas de filmes italianos contemporâneos. Com os diálogos selecionados, criamos um formulário composto por 16 questões, uma para cada vídeo, introduzidas por uma explicação geral para que os informantes soubessem de que modo cada pergunta deveria ser respondida. Os informantes foram orientados a, após assistirem a cada cena, classificarem o ato de fala principal, transcrito abaixo de cada vídeo, como ordem ou como pedido. Havia ainda um terceiro campo (outro), que estava em aberto para que pudessem descrever a ação que, conforme sua percepção, fosse mais apropriada. Além disso, pedimos especial atenção para que, após cada resposta, em um espaço que deixamos para essa finalidade, os informantes buscassem descrever os fatores que haviam motivado suas escolhas.

\subsection{OS INFORMANTES}

Em um período aproximado de três meses, recebemos respostas de 40 informantes italianos e 40 informantes brasileiros, cujas principais características foram resumidas na Tabela 1:

TABELA 1 - Dados gerais sobre os informantes italianos e brasileiros

\begin{tabular}{|c|l|l|l|l|}
\hline INFORMANTES & F & M & IDADE & $\begin{array}{l}\text { CURSO SUPERIOR COMPLETO/EM } \\
\text { ANDAMENTO }\end{array}$ \\
\hline IT & $65 \%$ & $35 \%$ & $19-59$ anos & $77,5 \%$ \\
\hline BR & $80 \%$ & $20 \%$ & $22-69$ anos & $85 \%$ \\
\hline
\end{tabular}

Fonte: Elaborada pelas autoras.
Quanto ao nível de conhecimento da língua italiana, cinco dos informantes brasileiros se autodeclararam de nível elementar, 15 de nível intermediário e 20 de nível avançado. Além do nível de conhecimento da língua italiana, pedimos que esses informantes, utilizando uma escala de 1 a 5 , indicassem a frequência de uso do italiano no seu dia a dia. Em ambos os casos, as medidas se basearam na autoavaliação e na percepção dos próprios aprendizes sobre sua competência em italiano e sobre o uso da língua, o que nos permitiu ter um quadro sobre a percepção que tinham de si mesmos como usuários da língua. Na Tabela 2, as porcentagens obtidas a partir dos resultados:

TABELA 2 - Nível de conhecimento da língua italiana dos informantes brasileiros e frequência de uso do italiano no dia a dia

\begin{tabular}{|l|c|c|c|c|c|c|c|}
\hline $\begin{array}{l}|l| \\
\text { NÍVEL DE CONHECIMENTO DA LÍNGUA } \\
\text { ITALIANA }\end{array}$ & \multicolumn{5}{l|}{$\begin{array}{l}\text { FREQUENCIA DE USO DO ITALIANO NO } \\
\text { DIA A DIA }\end{array}$} \\
\hline Elementar & Intermediário & Avançado & $\mathbf{1}$ & $\mathbf{2}$ & $\mathbf{3}$ & $\mathbf{4}$ & $\mathbf{5}$ \\
\hline $12,5 \%$ & $37,5 \%$ & $\mathbf{5 0 \%}$ & $22,5 \%$ & $\mathbf{4 0 \%}$ & $15 \%$ & $15 \%$ & $7,5 \%$ \\
\hline
\end{tabular}

Fonte: Elaborada pelas autoras.

Percebemos que, embora metade da amostra se autodeclara de nível avançado, a maioria dos aprendizes que responderam ao questionário afirma usar o italiano com uma frequência definida por eles entre média e baixa. Podemos dizer, portanto, que se trata de pessoas cujo contato com a língua italiana se limita essencialmente ao contexto de aprendizagem no Brasil.

\subsection{Metodologia de ANÁLISE dos dados}

Ao analisar os dados coletados para o desenvolvimento desta pesquisa, concentramo-nos em verificar como os informantes classificaram os atos de fala presentes em cada interação e que fatores motivaram suas respostas. A análise da classificação foi realizada pelo levantamento do número de 
informantes que, diante de cada enunciado, optou por uma das alternativas propostas ("ordem" ou "pedido"), ou então preencheu o campo "outro" que estava em aberto. Já para analisar as justificativas fornecidas pelos informantes, elaboramos uma categorização, da qual emergiram elementos dos seguintes tipos: (1) prosódico, (2) contextual, (3) pragmático e (4) pragmalinguístico.

Os elementos prosódicos, conforme indicado pelo trabalho de De Meo e Pettorino (2013), são as características da fala relacionadas à intensidade, ritmo, tom e entonação. Assim, inserimos nessa categoria o tom utilizado pelo falante e a velocidade com que o ato de fala foi proferido.

A classe dos elementos contextuais foi pensada a partir do conceito de contexto de Bazzanella (2008), mais especificamente naquilo que autora chama "contexto global", que se refere a elementos prevalentemente sociolinguísticos, dados por determinada situação comunicativa (participantes ou pessoas, localização, agentes). Nessa categoria, inserimos a relação entre os interlocutores, o modo como os participantes se vestem e os detalhes sobre o ambiente onde ocorre a interação.

Classificamos a descrição das consequências do ato de fala sobre o interlocutor e a cortesia como elementos que mais se relacionam ao efeito propriamente dito da língua em uso. Desse modo, retomando o conceito de Pragmática sugerido por Crystal (2008), criamos a categoria dos elementos pragmáticos, que abrange reflexões mais amplas dos falantes que consideram, ao mesmo tempo, normas sociais e aspectos linguísticos.

Por fim, a quinta categoria é aquela na qual agrupamos os elementos pragmalinguísticos, ou seja, aqueles que causam um efeito sobre os interlocutores, mas são expressos por meio dos recursos que a língua fornece para transmitir determinados enunciados, conforme afirma Leech (1983). Nessa categoria, agrupamos a estrutura linguística, $o$ ato de agradecimento, os atos de suporte, os modificadores (atenuadores/reforçadores) ou sua ausência e a repetição do enunciado.

Uma vez identificados e classificados os aspectos mencionados pelos informantes em suas justificativas, iniciamos o processo de análise, verificando, além do número de ocorrências, em que situação e com quais consequências apareceram na interpretação da percepção de cada ato de fala.

\section{RESULTADOS}

Na Tabela 3, apresentamos para cada um dos vídeos as variáveis analisadas e o percentual de informantes italianos e brasileiros que considerou cada caso como "ordem", "pedido" ou "outro".

TABELA 3 - Dados obtidos dos informantes italianos e brasileiros

\begin{tabular}{|c|c|c|c|c|c|c|c|c|}
\hline \multirow{2}{*}{ vÍDEO } & \multirow{2}{*}{$\begin{array}{l}\text { RELAÇÃO } \\
\text { ENTRE OS } \\
\text { INTERLOCUTORES }\end{array}$} & \multirow{2}{*}{$\begin{array}{l}\text { ESTRUTURA } \\
\text { LINGUÍSTICA }\end{array}$} & \multicolumn{2}{|c|}{ PEDIDO } & \multicolumn{2}{|l|}{ ORDEM } & \multicolumn{2}{|c|}{ OUTRO } \\
\hline & & & (IT) & (BR) & (IT) & (BR) & (IT) & (BR) \\
\hline 1 & $(A=B)$ & PCM & $95 \%$ & $82,5 \%$ & $5 \%$ & $17,5 \%$ & $0 \%$ & $0 \%$ \\
\hline 2 & $(A=B)$ & PCM & $67,5 \%$ & $57,5 \%$ & $22,5 \%$ & $32,5 \%$ & $10 \%$ & $10 \%$ \\
\hline 3 & $(A=B)$ & ICM & $65 \%$ & $55 \%$ & $27,5 \%$ & $37,5 \%$ & $7,5 \%$ & $7,5 \%$ \\
\hline 4 & $(A=B)$ & ICM & $40 \%$ & $30 \%$ & $27,5 \%$ & $57,5 \%$ & $32,5 \%$ & $12,5 \%$ \\
\hline 5 & $(A=B)$ & PSM & $80 \%$ & $90 \%$ & $20 \%$ & $7,5 \%$ & $0 \%$ & $2,5 \%$ \\
\hline 6 & $(A=B)$ & PSM & $90 \%$ & $100 \%$ & $0 \%$ & $0 \%$ & $10 \%$ & $0 \%$ \\
\hline 7 & $(A=B)$ & ISM & $22,5 \%$ & $20 \%$ & $70 \%$ & $62,5 \%$ & $7,5 \%$ & $17,5 \%$ \\
\hline 8 & $(A=B)$ & ISM & $7,5 \%$ & $2,5 \%$ & $70 \%$ & $87,5 \%$ & $22,5 \%$ & $10 \%$ \\
\hline 9 & $(A>B)$ & PCM & $62,5 \%$ & $75 \%$ & $15 \%$ & $10 \%$ & $22,5 \%$ & $15 \%$ \\
\hline 10 & $(A>B)$ & ICM & $10 \%$ & $7,5 \%$ & $82,5 \%$ & $90 \%$ & $7,5 \%$ & $2,5 \%$ \\
\hline 11 & $(A>B)$ & PSM & $32,5 \%$ & $45 \%$ & $55 \%$ & $40 \%$ & $12,5 \%$ & $15 \%$ \\
\hline
\end{tabular}




\begin{tabular}{|c|c|c|c|c|c|c|c|c|}
\hline \multirow{2}{*}{ VÍDEO } & \multirow{2}{*}{$\begin{array}{l}\text { RELAÇÃO } \\
\text { ENTRE OS } \\
\text { INTERLOCUTORES }\end{array}$} & \multirow{2}{*}{$\begin{array}{l}\text { ESTRUTURA } \\
\text { LINGUÍSTICA }\end{array}$} & \multicolumn{2}{|c|}{ PEDIDO } & \multicolumn{2}{|l|}{ ORDEM } & \multicolumn{2}{|c|}{ OUTRO } \\
\hline & & & (IT) & (BR) & (IT) & (BR) & (IT) & (BR) \\
\hline 12 & $(A>B)$ & ISM & $0 \%$ & $2,5 \%$ & $97,5 \%$ & $97,5 \%$ & $2,5 \%$ & $0 \%$ \\
\hline 13 & $(A<B)$ & PCM & $97,5 \%$ & $95 \%$ & $0 \%$ & $0 \%$ & $2,5 \%$ & $5 \%$ \\
\hline 14 & $(\mathrm{~A}<\mathrm{B})$ & ICM & $52,5 \%$ & $77,5 \%$ & $10 \%$ & $10 \%$ & $37,5 \%$ & $12,5 \%$ \\
\hline 15 & $(A<B)$ & PSM & $92,5 \%$ & $92,5 \%$ & $5 \%$ & $2,5 \%$ & $2,5 \%$ & $5 \%$ \\
\hline 16 & $(A<B)$ & ISM & $10 \%$ & $10 \%$ & $80 \%$ & $90 \%$ & $10 \%$ & $0 \%$ \\
\hline
\end{tabular}

(PCM = pergunta com modificador; $\mathrm{PSM}=$ pergunta sem modificador; ICM = imperativo com modificador; ISM = imperativo sem modificador)

Fonte: Elaborada pelas autoras.

A visão geral sobre os dados, permite observar que, diferente do que havíamos previsto, dos 16 vídeos apresentados, 14 não apresentaram divergências nas avaliações de italianos e brasileiros, pois foram classificados do mesmo modo pela maioria dos informantes.

Os dois únicos que tiveram resultados diferentes foram o vídeo 4 , no qual a relação entre os interlocutores é horizontal $(A=B)$ e o ato de fala é proferido pelo modo imperativo acompanhado de um modificador (ICM); e o vídeo 11, no qual há uma relação hierárquica entre os interlocutores $(A>B)$ e a estrutura linguística utilizada para proferir o enunciado é a pergunta sem o modificador (PSM), como evidenciado em cinza na tabela.

Considerando os pressupostos teóricos deste trabalho, em especial, no que diz respeito à relação entre os interlocutores (BROWN; LEVINSON, 1987) e à forma linguística que caracteriza os dois atos de fala (SERIANNI, 1991; KERBRATORECCHIONI, 2005; NUZZO, 2007), podemos dizer que o vídeo 4 conteria mais elementos que deveriam levar à classificação de um pedido e não de uma ordem, já que (i) não há diferença de poder; e (ii) o ato de fala proferido está no modo imperativo, mas com um modificador, cuja função é mitigar a força ilocutória do ato. De fato, a maioria dos informantes italianos vai ao encontro do que defendem os estudos e julgou se tratar de um pedido com as seguintes justificativas:

- a presença do modificador dai, que pode ser considerado uma estratégia a que os falantes recorrem quando buscam expressamente a colaboração do ouvinte;

- a relação entre os interlocutores, interpretada como vertical, com o falante A que se encontra em posição hierarquicamente inferior ao ouvinte $B(A<B)$, o que, segundo as condições de adequação ou felicidade descritas em Austin (1990), Searle (2002) e Sbisà (2009), não lhe permite o proferimento de atos assertivos, como no caso das ordens.

Além disso, outro aspecto mencionado com frequência pelos informantes foi o "tom" utilizado no vídeo, classificado como "de súplica", "não severo" e "pouco decidido". A importância atribuída ao "tom" confirma o que defendem estudos como os de Moretti e Orvieto (1984) e Serianni (1991), segundo os quais a entonação seria um traço que permitiria diferenciar os dois atos de fala. Cabe explicitar aqui que aquilo que os informantes indicam utilizando a palavra 'tom' parece reunir todas as características prosódicas, incluindo entonação, ritmo e intensidade (DE MEO; PETTORINO, 2013).

Diferentemente do que foi dito pela maioria dos falantes nativos que responderam ao questionário, para a maioria dos informantes brasileiros, o enunciado do vídeo 4 é uma ordem. É interessante observar que os âmbitos aos quais se faz referência nas justificativas são os mesmos (relação entre os interlocutores; forma linguística; entonação), mas suas interpretações vão no sentido oposto, já que (a) a relação entre os interlocutores foi interpretada como vertical, com A superior a $B(A>B)$, criando as condições necessárias para o proferimento de atos mais assertivos como as ordens; (b) o uso do imperativo foi considerado um indicador da presença de uma ordem; (c) o tom utilizado pelo falante, foi classificado como "assertivo".

A respeito do vídeo 11, o enunciado apresenta tanto as características da ordem quanto aquelas do pedido. Por um lado, poderia se tratar de uma ordem por estar o interlocutor $\mathrm{A}$ em uma posição social hierarquicamente superior à de $B$, o que lhe atribuiria esse direito; por outro, entretanto, também poderia 
ser um pedido, já que a estrutura linguística utilizada para a realização do ato é a pergunta que, conforme afirma Searle (2002), é frequentemente utilizada para diminuir a força ilocutória.

Para a maioria dos informantes italianos, o enunciado apresentado nesse vídeo é uma ordem. Um dos aspectos mais citados para justificar sua escolha foi o efeito do ato sobre o interlocutor, o que foi apontado por Sbisà (2009) como essencial para diferenciar ordens e pedidos. Para esses informantes, ao ouvinte está sendo atribuído um "dever", já que ele parece não ter liberdade para escolher entre aceitar ou recusar o que lhe é dito. Os outros dois aspectos que aparecem entre os mais mencionados são, mais uma vez, o "tom" e a distância entre os interlocutores. 0 "tom", segundo elemento mais citado, foi qualificado como "imperativo", "decidido" e "autoritário"; e a relação entre os interlocutores foi interpretada como vertical, com o falante A em condições de dar ordens ao ouvinte $B(A>B)$.

Já, para a maioria dos informantes brasileiros, o enunciado do vídeo 11 foi interpretado como pedido. Nas suas justificativas, os elementos mencionados com maior frequência foram os seguintes: (a) o tom utilizado pelo falante; (b) a pergunta como estrutura linguística na realização do ato; (c) o efeito do ato sobre o interlocutor. $\mathrm{Na}$ avaliação desses informantes, o ouvinte parece, além disso, ter liberdade para escolher entre aceitar ou recusar o que lhe é solicitado, ou seja, o que está sendo atribuído é um "poder" e não um "dever".

Passando agora aos vídeos classificados da mesma forma pela maioria tanto dos italianos quanto dos brasileiros, a análise mostrou que, com exceção dos vídeos 1 e 16, os principais elementos que motivaram a indicação de uma determinada classificação não foram os mesmos ou não ocorreram com a mesma frequência.

No vídeo 1, classificado como pedido pela maioria dos brasileiros $(82,5 \%)$ e dos italianos (95\%), foram citados nas justificativas os mesmos três elementos: (i) o uso do modificador per favore; (ii) o tom utilizado pelo falante; e (iii) a relação entre os interlocutores. Para o vídeo 16, que para a maioria dos brasileiros (90\%) e dos italianos (80\%) era uma ordem, os três elementos mais citados foram: (i) o tom utilizado pelo falante; (ii) a repetição do enunciado; e (iii) o modo imperativo.

Em cinco dos 14 casos em que o ato de fala foi classificado da mesma maneira, somente o primeiro elemento mencionado com maior frequência era o mesmo. Vejamos, por exemplo, os resultados do vídeo 5, classificado pela maioria dos dois grupos como pedido. Nas justificativas apresentadas pelos brasileiros, os elementos mais mencionados foram, em ordem de maior frequência: o tom utilizado pelo falante; a relação entre os interlocutores; a presença da pergunta na realização do ato. Os informantes italianos também mencionaram o tom utilizado pelo falante, em primeiro lugar, mas, em seguida, apareceram: a presença da pergunta na realização do ato e o efeito do ato sobre o interlocutor

Ao fazer um levantamento geral dos elementos mencionados nas justificativas de todos os 80 informantes, buscamos identificar as categorias mais utilizadas pelos dois grupos, que estão, com as respectivas porcentagens, no Gráfico 1:

GRÁFICO 1 - Levantamento geral dos elementos mencionados por brasileiros e italianos

\section{Gráfico 1: Categorias mais citadas (\%)}

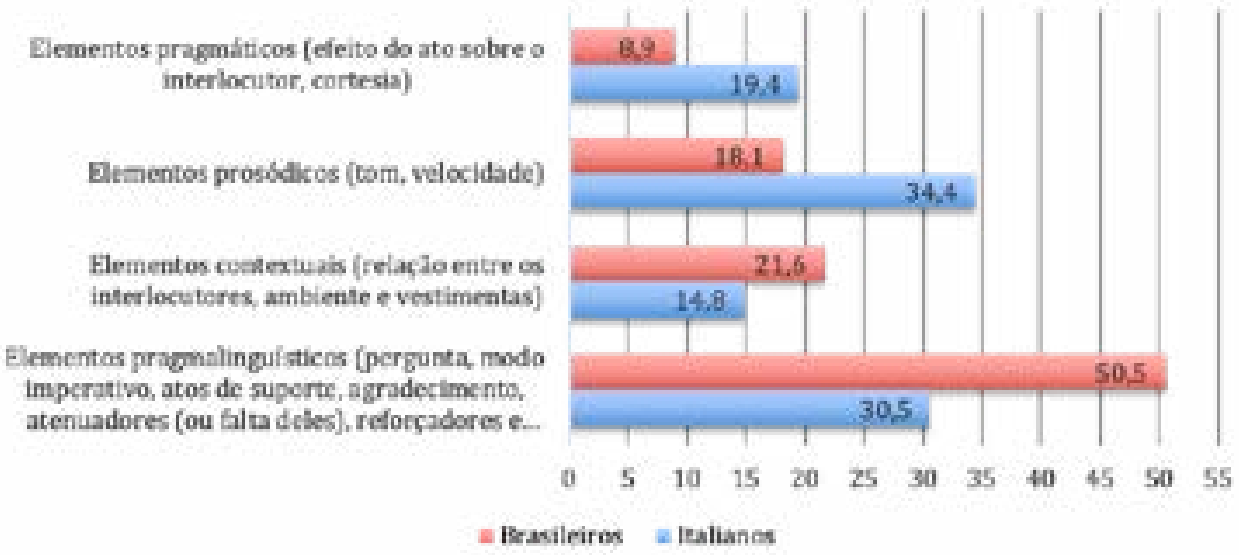

Fonte: Spadotto (2016).

Vê-se que, embora todos os aspectos mencionados pelos italianos foram também citados pelos brasileiros, nas justificativas dos falantes nativos, prevaleceu a referência a elementos prosódicos, ou seja, ao tom e à velocidade com que os enunciados eram proferidos. Em seguida, aparecem os elementos pragmalinguísticos, incluindo a pergunta ou o modo imperativo; os atos de suporte, que geralmente introduziam os atos principais; o ato do agradecimento, presente em algumas interações; a presença (ou ausência) dos elementos 
atenuadores; os elementos reforçadores; a repetição do enunciado. 0 terceiro lugar é ocupado pelos elementos pragmáticos, onde inserimos o efeito do ato sobre o interlocutor assim como definido por Crystal (2008) e Sbisà (2009) e a cortesia no sentido apontado por Brown e Levinson (1987). Por fim, encontramse os elementos ligados ao contexto "dado" (SBISÀ, 2002; BAZZANELLA, 2008), que incluem a relação entre os interlocutores, as vestimentas e os detalhes do ambiente onde ocorreu a interação. Já nas justificativas dos aprendizes brasileiros, a categoria mais citada foi a dos elementos pragmalinguísticos; em segundo lugar, estão os elementos contextuais; em seguida, os prosódicos, enquanto os elementos pragmáticos aparecem só no quarto lugar.

Os dados indicam, portanto, que se, por um lado, a hipótese de que haveria divergências na classificação de ordens e pedidos por parte de italianos e brasileiros foi desmentida, por outro, confirma-se que há diferenças na seleção das justificativas. De fato, embora os aspectos mencionados para justificar as escolhas sejam os mesmos, a diferente frequência com a qual são citados aponta para distintas maneiras de perceber os atos de fala na língua que está sendo observada.

\section{CONSIDERAÇõES FINAIS}

Uma vez apresentados os resultados, podemos retomar as perguntas que guiaram o estudo. Em primeiro lugar, era nosso objetivo tentar identificar quais elementos caracterizam esses dois atos de fala, a partir da percepção de falantes nativos e aprendizes brasileiros de italiano.

Observando os dados dos falantes nativos e focalizando as variáveis que manipulamos (a relação entre os interlocutores e as estruturas linguísticas utilizadas), percebemos que há uma tendência em classificar um ato de fala como pedido quando não há hierarquia entre os participantes da interação, ou seja, quando a relação é horizontal $(A=B)$ e quando o falante é socialmente inferior ao ouvinte, o que configura a relação como vertical $(A<B)$. Já, quando há diferença de poder relativo entre os interlocutores e a relação é vertical, mas em sentido oposto $(A>B)$, o ato tende a ser interpretado como ordem.

Quanto à estrutura linguística, verificamos que um ato tende a ser classificado como pedido, quando é realizado pela pergunta ou quando o falante usa modificadores linguísticos que atenuam sua força ilocutória. No caso de enunciados que são proferidos com o modo imperativo e, sobretudo, sem elementos mitigadores, $\mathrm{o}$ ato tende a ser interpretado como ordem.

Ao analisar os outros elementos presentes nas justificativas dos falantes nativos, verificamos que, em sua avaliação, um ato se configura como pedido quando é acompanhado de atos de suporte e de agradecimento, quando são reconhecidos elementos pragmáticos que definem a cortesia e a proteção da face positiva e negativa (GOFFMAN, 1969; BROWN; LEVINSON, 1987) e quando o efeito do ato sobre o interlocutor se configura na liberdade do ouvinte em aceitar ou recusar o que é dito pelo falante, isto é, pela atribuição de um 'poder', assim como definida por Sbisà (2009). Outro aspecto escolhido pelos informantes italianos para distinguir os atos de fala é o prosódico, ao qual eles muitas vezes se referem com a palavra "tom" confirmando o que é dito em relação à importância da entonação em gramáticas como a de Moretti e Orvieto (1984) e Serianni (1991). Na caracterização dos pedidos, a descrição desse elemento é acompanhada de adjetivos como "gentil", "tranquilo" e "não autoritário". Justifica-se, ao contrário, a decisão de classificar um ato de fala como ordem, dizendo que o tom utilizado pelo falante é "autoritário", "seco", "ríspido" e "direto".

Também se considera um ato como ordem, quando há aspectos do contexto ou outros elementos que reforçam a percepção de uma relação hierárquica entre os interlocutores. Além disso, um ato é percebido como ordem pelo efeito que tem sobre o interlocutor, isto é, quando o ouvinte não tem liberdade de escolha e assim "deve" aceitar o que o falante quer que ele faça.

Quando a avaliação dos atos de fala é realizada pelos aprendizes brasileiros de italiano, em relação às variáveis manipuladas, as respostas mostraram as mesmas tendências que observamos para os nativos. No que concerne à relação entre os interlocutores, um ato de fala tende a ser percebido como pedido quando não há hierarquia entre os participantes da interação $(A=B)$ e quando o falante é hierarquicamente inferior a ouvinte $(A<B)$. Porém, quando a relação se caracteriza por diferenças no poder relativo e o falante $A$ é hierarquicamente superior ao ouvinte $\mathrm{B}, \mathrm{o}$ ato tende a ser interpretado como ordem.

A respeito da estrutura linguística, observamos que um ato tende a ser classificado como pedido, quando é realizado pela pergunta ou quando o falante recorre a modificadores que atenuam sua força ilocutória, e como ordem, quando o enunciado é proferido com o modo imperativo e sem elementos mitigadores. 
Também observamos que, para os brasileiros, um ato pode ser interpretado como ordem ou pedido a partir de aspectos diferentes em relação às variáveis que manipulamos e praticamente não há diferenças entre aquilo que constatamos nas respostas dos falantes nativos. Do ponto de vista pragmalinguístico, para os brasileiros, pedidos, diferentemente de ordens, são acompanhados de atos de suporte, considerando, em especial, o agradecimento, geralmente proferido após $o$ ato principal. Também configuram um ato como pedido, diferenciando-o de uma ordem, elementos pragmáticos como a cortesia e a liberdade que o ouvinte tem para aceitar ou recusar o que é dito pelo falante (atribuição de um "poder"). A respeito dos elementos prosódicos mencionados, um ato de fala é um pedido quando o tom com que é proferido é "não imperativo", "gentil" e "não autoritário", enquanto uma ordem se caracteriza pelo tom "imperativo" "assertivo" e "sério". Mais um fator que leva a considerar um ato como ordem são os aspectos do contexto que evidenciam a relação de hierarquia entre os interlocutores. Além disso, para os brasileiros, um ato de fala é uma ordem pelo efeito que tem sobre o interlocutor, ou seja, quando o ouvinte parece não poder escolher entre aceitar ou recusar o que lhe é dito porque há a atribuição de um "dever", conforme descreve Sbisà (2009).

Após termos identificado as características de cada grupo de informantes, passamos à comparação entre eles, em busca de convergências e divergências. Verificamos que todos os elementos mencionados pelos falantes nativos foram também identificados pelos aprendizes, o que poderia ser um indício de que brasileiros e italianos reconhecem os mesmos elementos no proferimento de ordens e pedidos e na diferença entre esses dois atos de fala. Esse primeiro indício se confirma quando, ao observar os dados gerais, constatamos que dos 16 vídeos apresentados, somente dois não foram classificados do mesmo modo pela maioria dos informantes italianos e brasileiros.

Entretanto, ao analisarmos as justificativas presentes nas respostas dos vídeos que foram classificados da mesma maneira, percebemos que, com exceção dos vídeos 1 e 16, os principais elementos que motivaram os informantes brasileiros e italianos a atribuir uma determinada classificação não foram os mesmos ou não foram indicados com a mesma frequência em todos os outros casos. Encontra-se aqui a principal diferença entre os dois grupos.

Nas justificativas dos falantes nativos, foi possível constatar que os elementos mencionados com maior frequência foram os prosódicos, seguidos pelos pragmalinguísticos, pelos pragmáticos e, por fim, pelos contextuais. Já nas justificativas dos brasileiros aprendizes de italiano, a categoria mais citada foi a dos elementos pragmalinguísticos, logo após, apareceram os elementos contextuais, em terceiro lugar, os prosódicos e, então, os pragmáticos.

Os brasileiros basearam-se, portanto, fundamentalmente na estrutura da língua para julgar os enunciados, enquanto os italianos observaram mais frequentemente aspectos prosódicos e pragmáticos para justificar suas respostas. Esse resultado poderia indicar que a competência pragmática se desenvolve depois da competência linguística, conforme apontado por estudos como o já citado de Salsbury e Bardovi-Harlig (2001).

Contudo, tendo em vista que a maioria dos nossos informantes tem um nível de conhecimento da língua italiana definido por eles próprios intermediário ou avançado, acreditamos que os resultados obtidos se aproximam mais daquilo que, como dissemos, foi constatado pelo estudo de Vedder (2007), no qual, observando-se o uso de modificadores linguísticos, não se considerou confirmada uma possível relação entre progressão linguística e desenvolvimento da competência pragmática.

Desse modo, poderíamos supor que o fato de os aprendizes brasileiros terem se apoiado mais frequentemente em elementos gramaticais, assim como em geral são apresentados nos livros didáticos, aponte para a falta de contextualização e de modelos reais de uso da língua. É nesse contexto que se inserem os questionamentos que apresentamos, contidos em Rose e Kasper (2001) sobre quais seriam, de fato, as oportunidades oferecidas em sala de aula para que a competência pragmática seja desenvolvida e se a competência pragmática pode ser desenvolvida sem instruções específicas.

Os dados da nossa pesquisa apontariam para a ausência ou escassez de oportunidades que possam proporcionar uma reflexão sobre o papel da Pragmática no uso da língua. Estudos futuros, realizados aumentando o número de informantes e selecionando aprendizes com níveis diferentes de competência linguística, poderão contribuir para confirmar e aprofundar essas primeiras conclusões, além de permitir verificar a existência de eventuais correlações entre o nível de competência e a percepção de aspectos pragmáticos. Desse modo, será possível continuar o diálogo entre a prática de sala de aula e a pesquisa empírica que, diferente da simples intuição, pode fornecer suporte para o ensino e a aprendizagem de uma língua estrangeira. 


\section{REFERÊNCIAS}

ACHIBA, Machiko. Learning to request in a second language: a study of child interlanguage pragmatics. Clevedon: Multilingual Matters, 2003. https://doi.org/10.1017/s0047404504245055

AUSTIN, John Langshaw. Quando dizer é fazer: palavras e ação. Tradução de D. Marcondes de Souza Filho. Porto Alegre: Artes Médicas, 1990.

BARRON, Anne. Acquisition in interlanguage pragmatics: learning how to do things with words in a study abroad context. Amsterdam: John Benjamins, 2003. https://doi.org/10.1075/pbns.108

BAZZANELLA, Carla. Linguistica e pragmatica del linguaggio: un'introduzione. Roma: Laterza, 2008.

BLUM-KULKA, Shoshana; HOUSE, Juliane; KASPER, Gabriele (ed.). Cross-cultural pragmatics: requests and apologies. Norwood: Ablex, 1989. https://doi.org/10.1017/s0047404500016109

BROWN, Penelope; LEVINSON, Stephen. Politeness: some universals in language usage. Cambridge: Cambridge University, 1987. https://doi.org/10.1525/ae.1988.15.4.02a00420

CLANCY, Patricia. A case study in language socialization: Korean wh-question. Discourse Processes, Norwood, v. 12, n. 2, p. 169-191, 1989. https://doi.org/10.1080/01638538909544725

CRYSTAL, David. A dictionary of linguistics and phonetics. 6th ed. Malden: Blackwell, 2008.

CLANCY, Patricia. The acquisition of communicative style in Japanese. In: SCHIEFFELIN, Bambi; OCHS, Elinor (ed.). Language and socialization across-cultures. Cambridge: Cambridge University, 1986. p. 213-250. https://doi.org/10.1017/cbo9780511620898.011

DE MEO, Anna; PETTORINO, Massimo (ed.). Prosodic and rhythmic aspects of L2 acquisition: the case of Italian. Cambridge: Cambridge Scholars Publishing, 2013.

GOFFMAN, Erving. Interaction ritual: essays on face to face behavior. New York: Garden City, 1967.

GU, Yueguo. Politeness phenomena in modern Chinese. Journal of Pragmatics, Amsterdam, v. 14, n. 2, p. 237-257, 1990. https://doi.org/10.1016/0378-2166(90)90082-O

HILL, Beverly et al. Universals of linguistic politeness: quantitative evidence from Japanese and American English. Journal of Pragmatics, Amsterdam, v. 10, n. 3, p. 347-371, 1986. https:// doi.org/10.1016/0378-2166(86)90006-8

KERBRAT-ORECCHIONI, Catherine. Os atos de linguagem no discurso: teoria e funcionamento. Tradução de F. Afonso de Almeida e I. Dias. Niterói: Universidade Federal Fluminense, 2005.
IDE, Sachiko. Formal forms and discernment: two neglected aspects of linguistic politeness. Multilingua, Berlin, v. 8, n. 2-3, p. 223-248, 1989. https://doi.org/10.1515/mult.1989.8.2-3.223

LEECH, Geoffrey. Principles of pragmatics. London: Longman, 1983

MARQUEZ, Rosina. Linguistic politeness in Britain and Uruguay: a contrastive study of requests and apologies. Amsterdam: John Benjamins, 2000. https://doi.org/10.1075/pbns.83

MARTÍNEZ-FLOR, Alicia. Analysing request modification devices in films: implications for pragmatic learning in instructed foreign language contexts. In: ALCÓN-SOLER, Eva; SAFONTJORDÀ, Maria Pilar (ed.). Intercultural language use and language learning. The Netherlands: Springer, 2008. p. 245-280. https://doi.org/10.1007/978-1-4020-5639-0_13

MATSUMOTO, Yoshiko. Politeness and conversational universals: observations from Japanese Multilingua, Berlin, v. 8, n. 2-3, p. 207-221, 1989. https://doi.org/10.1515/mult.1989.8.2-3.207

MATSUMOTO, Yoshiko. Reexamination of the universality of face: politeness phenomena in Japanese. Journal of Pragmatics, Amsterdam, v. 12, n. 4, p. 403-426, 1988. https://doi. org/10.1016/0378-2166(88)90003-3

MORETTI, Giovanni Battisa; ORVIETO, Giorgio Raffaele. Grammatica italiana. Perugia: Editrice Benucci, 1984 .

NUZZO, Elena. Imparare a fare cose con le parole: richieste, proteste, scuse in italiano lingua seconda. Perugia: Guerra Edizioni, 2007.

NUZZO, Elena. La pragmatica nei manuali d'italiano L2: una prima indagine sull'atto linguistico del ringraziare. Revista de Italianística, São Paulo, n. 26, p. 5-30, 2013. https://doi.org/10.11606/ issn.2238-8281.v2i26p5-29

NUZZO, Elena. Lo sviluppo delle competenze pragmatiche. In: NUZZO, Elena; GAUCI, Phyllisienne Insegnare la pragmática in italiano L2: recenti ricerche nella prospettiva della teoria degli atti linguistici. Roma: Carocci, 2012.

NUZZO, Elena; SANTORO, Elisabetta. Apprendimento, insegnamento e uso di competenze pragmatiche in italiano L2/LS: la ricerca a partire dagli anni Duemila. E-JournALL, EuroAmerican Journal of Applied Linguistics and Languages, [s. l.], v. 4, n. 2, p. 1-27, 2017. https://doi. org/10.21283/2376905x.7.116

ROSE, Kenneth; KASPER, Gabriele (ed.). Pragmatics in language teaching. Cambridge: Cambridge University, 2001. https://doi.org/10.1017/CB09781139524797 
SALSBURY, Tom; BARDOVI-HARLIG, Kathleen. I know you mean, but I don't think so: disagreements in L2 English. In: BOUTON, L. F. (ed.). Pragmatics and language learning. Urbana: University of Illinois at Urbana-Champaign, 2001. v. 10, p. 131-151.

SANTORO, Elisabetta. A constituição de um corpus de italiano falado para o estudo de pedidos e pedidos de desculpas: considerações sobre a validade interna e externa dos dados. In: MELLO, Heliana; PETTORINO, Massimo; RASO, Tommaso (ed.). Proceedings of VII GSPC International Conference: speech and corpora. Firenze: Firenze University, 2012.

SANTORO, Elisabetta. Lo sviluppo della competenza pragmatica in italiano L2: un esperimento a partire da un corso online. In: RÜCKL, Michaela; SANTORO, Elisabetta; VEDDER, Ineke (org.). Contesti di apprendimento di italiano L2: tra teoria e pratica didattica. Firenze: Franco Cesati, 2013. p. 27-42. https://doi.org/10.11606/issn.2238-8281.v2i26p145-148

SBISÀ, Marina. Linguaggio, ragione, interazione: per una pragmatica degli atti linguistici. Trieste: Edizioni Università di Trieste, 2009.

SBISÀ, Marina. Speech acts in context. Language \& Communication, Oxford, v. 22, n. 4, p. 421436, 2002. https://doi.org/10.1016/S0271-5309(02)00018-6

SCHAUER, Gila A. May you speak louder maybe? Interlanguage pragmatic development in requests. EUROSLA Yearbook, Amsterdam, v. 4, n. 1, p. 253-273, 2004. https://doi.org/10.1075/ eurosla.4.12sch

SCHMITZ, John Robert. O debate sobre o falante nativo e não nativo: quais são os assuntos e quais os resultados? Calidoscópio, São Leopoldo, v. 11, n. 2, p. 135-152, 2013. https://doi. org/10.4013/cld.2013.112.04

SEARLE, John. Expressão e significado: estudos da teoria dos atos de fala. Tradução de Ana Cecília G. A. de Camargo e Ana Luiza Marcondes Garcia. São Paulo: Martins Fontes, 2002.

SERIANNI, Lucca. Grammatica italiana: italiano comune e lingua letteraria. Torino: UTET Libreria, 1991

SPADOTTO, Luciane do Nascimento. Ordens e pedidos em língua italiana: um estudo da percepção de falantes nativos e aprendizes brasileiros a partir da teoria dos atos de fala. 2016 Dissertação (Mestrado em Língua, Literatura e Cultura Italiana) - Programa de Pós-Graduação em Língua, Literatura e Culturas Italiana, Departamento de Letras Modernas, Faculdade de Filosofia, Letras e Ciências Humanas, Universidade de São Paulo, São Paulo, 2016.

TROSBORG, Anna. Interlanguage pragmatics: requests, complaints and apologies. Berlin: Mouton de Gruyter, 1995. https://doi.org/10.1515/9783110885286
VEDDER, Ineke. Competenza pragmatica e complessità sintattica in italiano L2: l'uso dei modificatori nelle richieste. Linguistica e Filologia, Bergamo, v. 25, n. 1, p. 99-123, 2007. 